\title{
Types of Student's Motivation for Physical Culture Classes at University
}

\author{
Irina Mikhailovna Kremenevskaya \\ Ural Federal University; Email: adeyemidany@gmail.com \\ Daniel Paskalyevich Adeyemi \\ Ural Federal University; Email: danrim@mail.ru
}

Doi:10.5901/mjss.2015.v6n6s4p115

\begin{abstract}
The article identified and dealt with different kinds of motivation that influence perceptions and attitudes of students in physical culture education at the University. By survey obtained information concerning the attitude of students to physical training. Obtained changes in the ways of teaching physical culture on the basis of different motivational systems for improving students' attitudes and education conscious attitude to physical culture.
\end{abstract}

Keywords: physical culture at University, types of motivation settings, student's attitude, changes ways of teaching, healthy lifestyle, theoretical lesson.

\section{Introduction}

The state supports the sphere of physical culture and sport calling it one of the priorities of preservation of the intellectual potential of the country. The federal target program "Development of physical culture and sports in Russian Federation in 2006 - 2015" confirms it. Therefore, the state has invested huge allocation for physical education in the system of higher education, suggesting that the educational process will develop the physical qualities, improve the reserve capacity of the organism, to form need in the regular physical exercising.

The relevance of the work is caused by that in conditions of a qualitative conversion of all aspects of society's life, increase requirements of physical education to young people are needed for a successful work. The alteration of educational system is set a task to a high school of fundamental and comprehensive improvement of professional training and physical education of future professionals. The change of a target directivity of physical education, the essence of what is to form a physical culture of a person, demands to increase the quality of teaching, elaboration of new pedagogical and organizational forms which provide individual oriented education and training. Based on this we have to know how motivate students to increase activity on physical culture classes.

Objectives of this article are

- to define and to analyze types of motivation of students to physical education for future changing during design of educational space at university ;

- to analyze student's answers in questionnaire on this theme for future changing educational process.

\section{Literature Review}

The problem of forming needs in physical activity should be studied in close connection with the increase of adaptation capabilities of students organism with their preferences and satisfaction of interest (Adeyemi, 2015).

Based on analyzed literature on physical education problems in high schools and also our own experience we can see that that physical education in high schools only increases levels of motional activity and physical development (Astafyev, 2009). As a rule, such problem as the formation of motivational and value attitude of students in physical education and the need to systematic physical activity (physical exercising, acclimation, life regime, personal hygiene, reasonable proportion of labor and rest activity etc.) rare for researches. In the process of physical education individual characteristics of students are not always considered. Physical training and its system of credits that are taken as a base of physical education do not have long-term motivating factor for the physical perfection for students (Vilenskiy, 2001).

According to references and studies of other universities we defined the following types of motivation of students to 
physical culture (Malozyemov, 2007; Mukhamitianov, 2008; Shinkorenko, 2008; Vydrin, 1991):

Health-improving motivation: opportunity to strengthen health and preventive healthcare. A big effect of physical exercises to human body is well-known for a long time and does not raise any doubts and now it can be studied in two directions: forming of a health promotion and decreasing of probability of diseases including occupational disease; remedial effect of physical exercises for various types of diseases.

Dynamic-motional motivation: continuous mental activity leads to a percent reduction the perception of information, to a large number of professional mistakes. Physical exercises for all the muscles of the body and also for the visual apparatus significantly increases the efficiency of relaxation unlike passive recreation because they cause changes in all systems of human body, foremost in circulatory and respiratory systems. Also we receive pleasure of the process of physical exercising and enjoy yourself (Martsinkovskaya, 1998).

Competition-competitive motivation: desire to improve your own sporting achievements. The human history, the process of evolution is based on a spirit of rivalry, on a spirit of competitive relationships. A desire to achieve a certain level in sport area and in competitions is one of the most powerful regulators and a significant motivation to physical exercises.

Esthetic motivation: includes improving the appearance and wish to make impression on other people (perfecting of the physique, stressing the best body features, increasing the plasticity of movements).

Communicative motivation: collective physical trainings contribute to the improvement between different social and sex groups.

Informative entertaining motivation: connected with the desire of human know his own body, his opportunities and then improve them by means of physical culture and sports. In many ways it is similar to a competition-competitive motivation but it is based on the desire to win oneself, own laziness, not an opponent in competition. This motivation is a desire to maximally use the physical capabilities of the body, to improve the physical condition and to improve personal physical development.

Professionally oriented motivation: connected with an improving physical trainings by focused on the professional qualities of students of different specialties, to increase the level of their preparation for the upcoming labor activity, to develop a psychophysical form for future profession.

Administrative motivation: the system of credits is introduced to get rating results, and physical culture is not exception. Getting a credit for this discipline, to get rating points and to be permitted to a session stimulate students to do sports.

Psychologically significant motivation: physical training positively effects on mental condition of young people, especially students: gaining confidence, relieve emotional stress, preventing the development of stress condition, relieve mental stress, recovery of mental working efficiency. Certain types of physical exercises are an indispensable means of neutralizing the negative emotions.

Educational motivation: physical culture and sport develop self-training and self-control skills. Systematic physical exercises contribute to the development of moral and volitional qualities and also educating of patriotism and civicism.

Status motivation: due to development of physical skills of younger generation their vitality increases. A preferment of a personal status in conflicts resolution with physical impact on another person and also an increasing of a vitality potential in extreme personal conflicts, activates the participation of young people in physical and sport activity.

Cultural motivation: this motivation comes from the impact on young people exerted by the media, society and social institutions in shaping the individual needs of the physical exercises. It is defined by the influence of the cultural environment, the laws of society and the laws "group".

\section{Methods}

At the present time development of high school in the field of physical culture depends on the level of activity and consciousness of students, their position to physical education as a discipline. At the same time there are some expenses in the educational process that has a negative impact on the students' attendance of practical training, their activity and initiative.

The problem of preservation and promotion of health of the younger generation is one of the important problems of human society. Today there are only summons to be healthy but actual practice shows deterioration of youth health. The modern levels of urbanization, progress in science and technology, comfort are the reasons of «motional hunger».

The issue of motivation to do sport and physical education at various times was in the focus of discussing by physical education specialists. However at this work the objective was formulated to see in a different light from student perspective and understand what influence on development or lack of interest in maintaining a healthy life-style, doing 
sport and studying necessary theoretical foundation for future changing during design of educational space at university.

The questioning was prepared to study out what's interesting to students in physical education, how they are versed in theory, what they do to maintain their health, and also to understand, how physical education specialists can influence on the attitude of students to health problems.

152 full-time first- and third-year students of different departments of Ural Federal University took part in the questioning. The questioning consisted of four sections:

- the first section was devoted to the subject of perception of the importance of health in human life;

- the second section dealt with problems, concerning assessment of the health by students;

- the third section consisted of subjects which help us to understand the students' attitude to physical education and healthy life-style;

- in the forth section we tried to find out the causes of decreased interest of young people in physical education, and the main subjects that would be interesting for students and help to increase interest in sport and health.

We use survey method to define different aspects, which have influence on physical culture classes at University (Kuramshina, 2003).

Based on research Novikov M.A., which highlights the structure of the methodology of pedagogic three components: the methodology of pedagogical research, the methodology of practical teaching activities and methodology of educational activity, we note that survey method is part of the pedagogical research and is based on the methodology of pedagogical research, so it can help us to define all aspects of motivations and their influence (Novikov, 2002). In the formation of the project activity often acts as a learning tool, performing a supporting role in relation to other types of educational activities. Design can also be a form of organization of pedagogical interaction in time and space, breaking up into two relatively independent lines of work of teachers and students.

Schedrovitsky G.P. distinguishes between two different species in the strategic plan of pedagogical design adaptation to the social environment and its conditions, and the improvement and transformation of the environment in accordance with their values, goals, beliefs (Schedrovitsky, 1993). It is based on these basic methodological concepts we choose the method of survey for future design and streamline the educational space of the University by means of physical culture. Accordingly based on the survey data, we will able to design the educational space of the university considering the motivational aspects that will be more relevant for students.

Therefore, the main causes of the decline in interest and activity of students on physical education lessons and causes of missing lessons are an essential part of the questionnaire:

- the variance of offered physical activity and physical abilities;

- low level of own physical development;

- the absence activities according to interests;

- critical attitude to professors and regime of the institution;

- high level of busyness and lack of time;

- the lack of knowledge on the effects of physical training on health;

- the lack of knowledge base, sports equipment;

There are few blocks in the questionnaire, which are accentuated to analyze the status of physical education in institution and to determine the social and pedagogical problems of solving the main task for the specialists of physical education - the formation of the physical requirements for physical education.

Also it is well known that the attitude to health, a healthy lifestyle is linked to the values of a person, i.e. what guidance a person has, which place the healthcare takes among other values.

\section{Results and Discussion}

To begin with point that there are change in attitude from first year-students to third-years students that have the largest knowledge base, which could provide them the university, to healthy life-style and physical education was interesting. The data of questionnaire shows: among third-year students $80 \%$ think that a health is a value with highest priority and it depends on the life-style. Among first-year students number of students who agree with this statement is less - $76 \%$. It proves the fact that $61 \%$ of third-year students try to take care of their health, doing sport and visiting specialized sports clubs, $39 \%$ among them adhere to proper nutrition, $33 \%$ keep regular hours. Among first-year students the indicators are slightly lower: $56 \%$ of students do sport, $9 \%$ keep regular hours, $44 \%$ adhere to proper nutrition. These results show that physical-culture education specialists work in the right direction and popularize a healthy life-style.

There is a sharp decline in attendance of physical education classes and accordingly increase of the percentage of 
students among third-year students who failed exams as contrasted to first-year students. In accordance with answers given in questionnaires the mail cause of non-attendance of physical education classes is coercion ( $27 \%$ of students), and also lack of organization and laziness of students.

To solve the problem of concernment of students in physical education classes establishment of several sections, where students can do such sport which is more interesting for them is planned in 2013.

It's worth noting if the fitness level is at a stable level in terms of theoretical knowledge related to the work of the human body during exercise, of its structure as a whole, etc. the first-year students are not efficient.

Since 2012 at the Department of Physical Education compulsory theoretical lessons were introduced, which aim to fill the gaps in the education of students. The effectiveness of such lessons is proved by these profiles: $44 \%$ of first-year students receive information about healthy life-style and the basics of physical training on physical training lessons, the rest of the students consider that the main source of knowledge is TV programs and different publications devoted to this topic. And only $9 \%$ of first-year students purposefully and regularly read professional literature.

The question was included in the questionnaire, which found out which knowledge in the field of physical education they want to get: $50 \%$ of the total percent of the students are interested in the methods of prevention of stress and fatigue, $35 \%$ of students are concerned in the issue of a balanced diet, $17 \%$ are interested in unconventional methods of recovery.

\section{Conclusion}

Data obtained from the survey and analysis of the literature allows us to talk that changes are needed in today's teaching of physical training on the basis of the motivational settings that have been proposed. In order to foster formation a socially active person in the conditions of University by means of physical culture and sport it is advisable to resolve the following tasks in classes:

- health promotion and sport lifestyle have become a norm for students;

- to increase the educational level of students and knowledge in the field of health technologies of physical education and sport;

- significantly improve the quality of physical education in universities;

- to provide students equal opportunities for physical education and sports;

- to implement a qualified, professionally trained teaching staff;

- to interest students in systematic physical education, sports, to form a healthy lifestyle and to fight bad habits.

\section{References}

Adeyemi D.P. (2015). Formation of the motivational-valuable relation to the physical culture in students in the social-cultural environment of the higher educational establishment. Mediterranean Journal of Social Sciences, Vol.6, No. 1, S.2, 109-113.

Astafyev, V. S. (2009). Theoretical aspects of physical culture formation of HEl students' personality. Theory and practice of physical culture, 8.

Kuramshina, Yu. F. (2003)Theory and methods of physical culture: text-book. Moscow: Soviet sport.

Malozemov, O. Yu., Kovalevskii, A. K., Prokopenko, V. I. (2007). Physical culture as integrating factor of students' health saving. Yekaterinburg: Publ. house AMB.

Martsinkovskaya, T. D. (1998). The history of psychology: text-book for students of the pedagogical universities. Moscow: VLADOS.

Mukhamitianov, F. D. (2008). Physical culture as social phenomenon and cultural phenomenon. Theory and practice of physical culture, 9.

Novikov A.M. (2002). Methodology of Education. Moscow: Egves

Shinkorenko, O. V., Logunov, V. I. (2008). Basic direction of demand formation in the systemic physical training classes in students of the technical university. Theory and practice of physical culture, 6 .

Vilenskiy, M. Ya. (2001). Basis substantial characteristics of pedagogical technology of personality physical culture formation. Physical culture: upbringing, education, and training, 3.

Vydrin, V. M. (1991). Physical culture of the students of higher educational establishments. Voronezh: Education. 